\title{
Field emission from crystalline niobium
}

\author{
Arti Dangwal Pandey, ${ }^{1,2, *}$ Günter Müller, ${ }^{1}$ Detlef Reschke, ${ }^{2}$ and Xenia Singer ${ }^{2}$ \\ ${ }^{1}$ FB C Physik, Bergische Universität Wuppertal, D-42097 Wuppertal, Germany \\ ${ }^{2}$ DESY, Notkestraße 85, D-22603 Hamburg, Germany
}

(Received 20 November 2008; published 25 February 2009)

\begin{abstract}
Appreciable suppression of field emission (FE) from metallic surfaces has been achieved by the use of improved surface cleaning techniques. In order to understand the effects of surface preparation on field emission, systematic measurements were performed on five single crystal and three large grain samples of high purity $(\mathrm{RRR}>300)$ niobium by means of atomic force microscope, x-ray diffraction, scanning electron microscope (SEM), and dc field emission scanning microscope. The samples were treated with buffered chemical polishing (BCP), half of those for $30 \mu \mathrm{m}$ and others for $100 \mu \mathrm{m}$ removal of surface layer, followed by a final high pressure water rinsing. These samples provided the emission at minimum surface fields of $150 \mathrm{MV} / \mathrm{m}$ and those with longer BCP treatment showed the onset of field emission at slightly higher fields. A low temperature $\left(\sim 150^{\circ} \mathrm{C}\right)$ heat treatment in a high vacuum $\left(10^{-6}\right.$ mbar $)$ chamber for 14 hours, on a selected large grain $\mathrm{Nb}$ sample, gives the evidence for the grain boundary assisted FE at very high fields of 250 and $300 \mathrm{MV} / \mathrm{m}$. Intrinsic field emission measurements on the present $\mathrm{Nb}$ surfaces revealed anisotropic values of work function for different orientations. Finally, an interesting correlation between sizes of all investigated emitters derived from SEM images with respect to their respective onset fields has been found, which might facilitate the quality control of superconducting radio-frequency cavities for linear accelerators.
\end{abstract}

DOI: 10.1103/PhysRevSTAB.12.023501

\section{INTRODUCTION}

Highly purified fine grain niobium sheets (RRR $>250)$ have been used worldwide for the fabrication of high gradient superconducting accelerator cavities in various projects like FLASH [1], SNS [2], and RIA [3]. Much attention has been given to the surface preparation and cleanliness techniques, which has suppressed significantly the enhanced field emission (FE) of electrons from the cavity surface and thus improved the regular cavity performance at high accelerating gradients, e.g., up to about $E_{\text {acc }}=30 \mathrm{MV} / \mathrm{m}$ for nine-cell $1.3 \mathrm{GHz}$ structures [4]. High pressure rinsing (HPR) with ultrapure water is used as a standard technique for the final cleaning of such cavities [5], while dry ice cleaning (DIC) has emerged recently to be a very effective tool in this respect [6]. The best DIC single crystal $\mathrm{Nb}$ sample did not provide any FE up to an electric surface field $E_{s}\left(\approx 2 E_{\text {acc }}\right)$ of $250 \mathrm{MV} / \mathrm{m}$. Further, the removal of field emitting particulates down to $400 \mathrm{~nm}$ size and partial smoothing of protrusion edges by DIC on the $\mathrm{Nb}$ surface was also reported. On the other hand, for the HPR method it is known that the typical pressures of 80-100 bar theoretically overcome the sticking force for particles of about $1-2 \mu \mathrm{m}$ size [5].

An approach towards improving the cavity fabrication for future linear accelerators like XFEL [7] and ILC [8] has

\footnotetext{
*Present address: Max-Planck-Institut fuer Kohlenforschung, Kaiser-Wilhelm-Platz 1, D-45470 Muelheim an der Ruhr, Germany. dangwal.pandey@mpi-muelheim.mpg.de
}

PACS numbers: $79.70 .+\mathrm{q}$

been made by using buffered chemically polished (BCP) large grain $\mathrm{Nb}(\mathrm{LGNb})$ or single crystal $\mathrm{Nb}(\mathrm{SCNb})$ instead of electropolished (EP) polycrystalline $\mathrm{Nb}$, which might be less expensive due to the elimination of sheet fabrication and related processes. Preliminary tests of single-cell cavities made from large grain $\mathrm{Nb}$ have yielded $E_{\text {acc }}$ up to $45 \mathrm{MV} / \mathrm{m}$, which is one of the highest values achieved yet [9]. Further research on multicell structures made from large grain or single crystal $\mathrm{Nb}$ is required before it can replace polycrystalline $\mathrm{Nb}$. It has also been reported recently that the grain boundaries on large grain $\mathrm{Nb}$ cavities provide some, although not dominant, contribution to the hot spots in corresponding thermal maps [10]. Since grain boundaries get easily contaminated by the segregation of impurities during the usual bakeout of cavities [11,12], it is interesting to investigate their role for field emission, too [13].

In this paper, we report on FE properties and surface characteristics of eight large grain and single crystal samples, measured by means of field emission scanning microscope (FESM) [14-16], scanning electron microscope (SEM), atomic force microscope (AFM), and $\mathrm{x}$-ray diffraction (XRD). In situ heat treatments at $150^{\circ} \mathrm{C}$ were performed on two samples and then measured again to find any change in corresponding FE properties. Intrinsic FE measurements on such high quality samples were possible due to their very smooth surfaces and the derived $\phi$ values for different crystal orientations will also be discussed here. Finally, a correlation between sizes of all investigated emitters derived from SEM images and their respective onset fields will be presented. 
TABLE I. Overview of the investigated single crystal and large grain $\mathrm{Nb}$ samples. (nm used for not measured samples).

\begin{tabular}{|c|c|c|c|}
\hline Sample & $\begin{array}{c}\text { Removed } \\
\text { material } \\
\text { using BCP }\end{array}$ & Orientation & $\begin{array}{c}\text { Surface } \\
\text { roughness }\end{array}$ \\
\hline SCNb1 & $30 \mu \mathrm{m}$ & (110) & $11.7 \mathrm{~nm}$ \\
\hline $\mathrm{SCNb} 2$ & $30 \mu \mathrm{m}$ & $(110)$ & $17.6 \mathrm{~nm}$ \\
\hline SCNb3 & $100 \mu \mathrm{m}$ & (110) & $7.0 \mathrm{~nm}$ \\
\hline $\mathrm{SCNb} 4$ & $100 \mu \mathrm{m}$ & $(111)$ & $6.2 \mathrm{~nm}$ \\
\hline SCNb5 & $100 \mu \mathrm{m}$ & $(100)$ & $7.5 \mathrm{~nm}$ \\
\hline LGNb1 & $30 \mu \mathrm{m}$ & $(110),(111),(110)$ & $100,110.5,62.7$ \\
\hline LGNb2 & $30 \mu \mathrm{m}$ & $\mathrm{nm}$ & $\mathrm{nm}$ \\
\hline LGNb3 & $100 \mu \mathrm{m}$ & (100), (110), (111) & $8.8,6.9,6.8$ \\
\hline
\end{tabular}

\section{SAMPLE PREPARATION AND SURFACE QUALITY CONTROL}

Five single crystal and three large grain $\mathrm{Nb}$ samples of $28 \mathrm{~mm}$ diameter were fabricated at DESY Hamburg. The RRR value of the material was at least 300 with Ta content of $\sim 300 \mathrm{ppm}$. First of all, the sample disks were produced by high pressure water jet cut of $30 \mathrm{~mm}$ diameter ingots followed by mechanical polishing of the surface up to $R_{a}<0.1 \mu \mathrm{m}$. These were then oxypolished and etched up to $\sim 5 \mu \mathrm{m}$, and annealed at $800^{\circ} \mathrm{C}$ for 2 hours to relieve the mechanical stress in the material. Afterwards the disks were electron beam welded to specially designed sample holders. Final surface preparation using $\mathrm{BCP}$ in $\mathrm{HF}(40 \%): \mathrm{HNO}_{3}(65 \%): \mathrm{H}_{3} \mathrm{PO}_{4}(85 \%)$ in volume ratio 1:1:2 at temperature $12-18^{\circ} \mathrm{C}$ has resulted in a mirrorlike surface. For half of the samples a surface damage layer of 30 and $100 \mu \mathrm{m}$ was removed, respectively, with the intention of finding the impact of longer BCP treatment on the FE properties of the sample surface. The details of samples with surface preparation, crystal orientations, and roughness are summarized in Table I.

The high resolution optical microscopic images of samples SCNb5 and LGNb3 in Figs. 1(a) and 1(b) demonstrate the appearance of different grains of niobium, and the AFM image in Fig. 1(c) provides the surface roughness value of $7.5 \mathrm{~nm}$ for $\mathrm{Nb}(100)$ oriented surface [Fig. 1(d)]. $100 \mu \mathrm{m}$ polished single crystal $\mathrm{Nb}$ surfaces possess less surface roughness $(6-7.2 \mathrm{~nm})$ than $30 \mu \mathrm{m}$ polished ones $(12-17.5 \mathrm{~nm})$, while the large grain samples become as smooth only for $100 \mu \mathrm{m} \mathrm{BCP}$. All the samples were especially marked during fabrication to adjust the sample po-

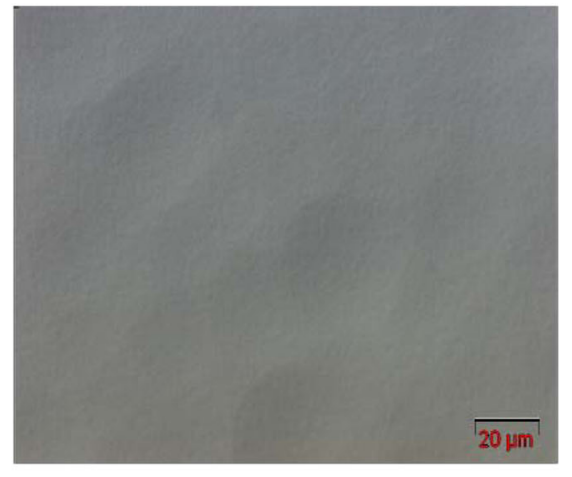

(a)

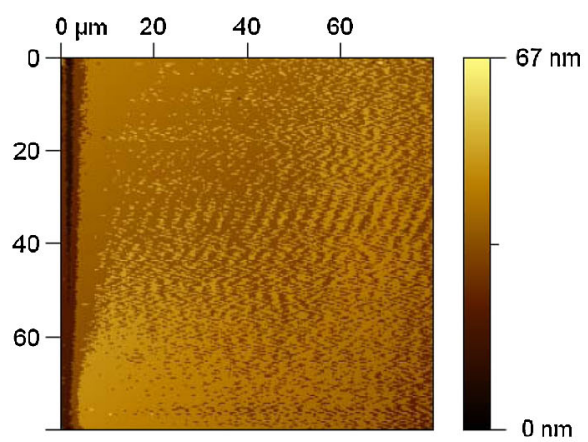

(c)

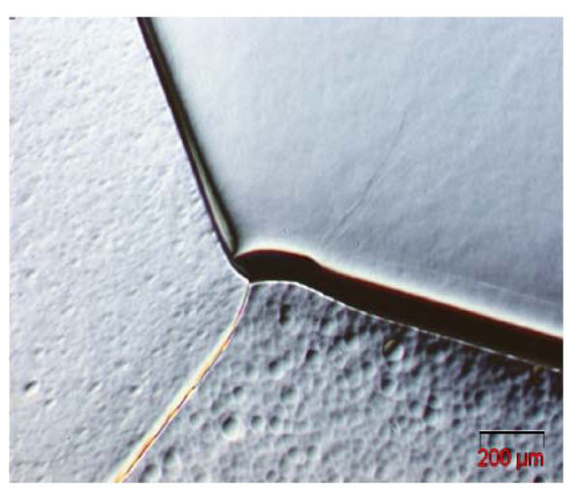

(b)

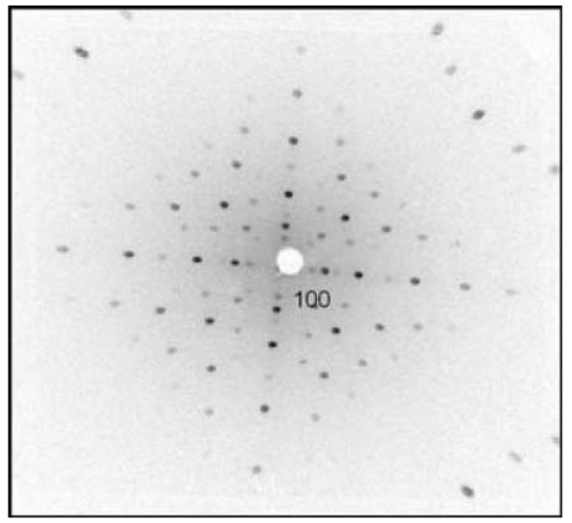

(d)

FIG. 1. (Color) (a) High resolution optical microscope image of sample SCNb5, (b) microscopic view of intersection of grain boundaries on large grain sample LGNb3, (c) AFM image of sample SCNb5 showing root mean square roughness of $7.5 \mathrm{~nm}$ over $(80 \times 80) \mu \mathrm{m}^{2}$ area, and (d) XRD image of SCNb5 revealing (100) orientation. 
TABLE II. Emitters observed in FE maps of all Nb samples (see Table I) at different field levels and the typical $\beta$ and $S$ values retrieved from local I-V measurements of emitters.

\begin{tabular}{lcccccc}
\hline \hline Sample & \multicolumn{3}{c}{ Number of emitters } \\
& $\begin{array}{c}120 \mathrm{MV} / \mathrm{m} \\
\text { over }(10 \mathrm{~mm})^{2}\end{array}$ & $\begin{array}{c}150 \mathrm{MV} / \mathrm{m} \\
\text { over }(7.5 \mathrm{~mm})^{2}\end{array}$ & $\begin{array}{c}\text { FN parameters } \\
\text { over }(5 \mathrm{~mm})^{2}\end{array}$ & $\begin{array}{c}250 \mathrm{MV} / \mathrm{m} \\
\text { over }(5 \mathrm{~mm})^{2}\end{array}$ & $\beta$ & $S\left(\mathrm{~m}^{2}\right)$ \\
\hline SCNb1 & 0 & 2 & 5 & $\ldots$ & 56 & $3.8 \times 10^{-20}$ \\
$\mathrm{SCNb} 2$ & 0 & 1 & 9 & $\ldots$ & 54 & $4.2 \times 10^{-19}$ \\
$\mathrm{SCNb3}$ & 0 & 0 & 3 & 9 & 32 & $4.4 \times 10^{-16}$ \\
$\mathrm{SCNb} 4$ & 0 & 0 & 2 & 7 & 29 & $5.6 \times 10^{-16}$ \\
$\mathrm{SCNb} 5$ & 0 & 0 & 2 & 3 & 24 & $1.4 \times 10^{-17}$ \\
$\mathrm{LGNb} 1$ & 2 & 5 & 10 & $\ldots$ & 48 & $2.7 \times 10^{-18}$ \\
$\mathrm{LGNb} 2$ & 0 & 3 & 12 & $\ldots$ & 41 & $1.3 \times 10^{-18}$ \\
LGNb3 & 0 & 1 & 4 & 11 & 54 & $1.4 \times 10^{-18}$ \\
\hline \hline
\end{tabular}

sition in different experimental setups and were finally rinsed with ultrapure water using a high pressure of 150 bar (nominal value for the used HPR system).

The FE measurements were performed on the flat $\mathrm{Nb}$ cathodes under ultrahigh vacuum conditions in FESM, using conical anodes. The samples were first scanned over a selected area of $(12 \times 12)$ and $(10 \times 10) \mathrm{mm}^{2}$ at 90 and $120 \mathrm{MV} / \mathrm{m}$ with $300 \mu \mathrm{m}$ anode, and then at 150 and 200 (or 250 and higher) $\mathrm{MV} / \mathrm{m}$ with $100 \mu \mathrm{m}$ anode over the areas of $(7.5 \times 7.5)$ and $(5 \times 5) \mathrm{mm}^{2}$, respectively. During scans, the applied voltage was regulated for $2 \mathrm{nA}$ current and anode-to-sample distance was varied from 50 to $20 \mu \mathrm{m}$ according to the required field using $5 \mathrm{kV}$ power supply. The strong emitters in the observed electric field $(E)$ maps were localized and studied for their individual FE properties. A resistive heating oven installed in the high vacuum chamber of FESM was used to heat the samples at $150( \pm 10)^{\circ} \mathrm{C}$. Efforts were made finally to identify the emitters ex situ in SEM and to reveal their origin from geometrical features and chemical compositions with energy dispersive $\mathrm{x}$-ray analysis (EDX).

\section{FIELD EMISSION RESULTS AND DISCUSSION}

\section{A. Statistical overview of the emitters}

All large grain and single crystal $\mathrm{Nb}$ samples have provided very good results, as summarized in Table II. FE maps on large grain $\mathrm{Nb}$ samples showed the onset of FE for $2 \mathrm{nA}$ current at $120 \mathrm{MV} / \mathrm{m}$ for $30 \mu \mathrm{m}$ and at $150 \mathrm{MV} / \mathrm{m}$ for $100 \mu \mathrm{m}$ polished surfaces. For single crystal $\mathrm{Nb}$ samples with 30 and $100 \mu \mathrm{m} \mathrm{BCP}$, the onset of $\mathrm{FE}$ was observed at $150 \mathrm{MV} / \mathrm{m}$ and $200 \mathrm{MV} / \mathrm{m}$, respectively. The typical FE maps, given in Fig. 2, show the observed emitters at the highest scanned field levels for these two cases. If we compare the number of emitters at different field levels for all samples from Table II, a marked difference between $30 \mu \mathrm{m}$ BCP'd LGNb samples (LGNb1 and 2) and all others is observed. It is interesting to discover that it can be directly related to the large difference in the surface roughness values, which is of the order of $100 \mathrm{~nm}$ for former and about $10 \mathrm{~nm}$ for the later (Table I). Thus, FE was strongly suppressed for smoother surfaces.

A statistical overview of the number density of emitters $N$ for varying electric field $E$ is presented in Fig. 3. In order to reduce the statistical error and to simplify the $N(E)$ plot, all the results for a particular kind of sample have been summed up, i.e., the corresponding areas and number of emitters were added at the given scanned field levels. Within statistical errors, for LGNb with 30 and $100 \mu \mathrm{m}$ $\mathrm{BCP}$, the onset of FE was observed at 120 and $150 \mathrm{MV} / \mathrm{m}$, while for $\mathrm{SCNb}$ at 150 and $200 \mathrm{MV} / \mathrm{m}$, respectively. Despite a significant statistical error, for more material removal there is a tendency of $N(E)$ exponential fit lines to shift to the right, i.e., to higher onset fields and an evidence for reduced slopes, i.e., less number density of field emitters at a given field level. For comparison with the best quality polycrystalline $\mathrm{Nb}$ sample ${ }^{1}$ electropolished inside a cavity at DESY [17,18], the corresponding fit line has also been plotted, showing clearly the better performance of $\mathrm{SCNb}$ and LGNb samples. These observations are consistent with the earlier findings that more than $50 \mu \mathrm{m}$ of the material thickness has to be removed for better cavity performance $[19,20]$.

As it is noticeable above that these samples could be measured at very high fields (150-200 MV/m), this is not the case for $\mathrm{rf}$ cavities. The tests on large grain $\mathrm{Nb} \mathrm{rf}$ cavities (six single-cell and three nine-cell) performed until now at DESY showed that the maximum gradients typically achieved are around $40 \mathrm{MV} / \mathrm{m}$ (i.e. $80 \mathrm{MV} / \mathrm{m}$ surface fields). In most of the cases, it was not limited by FE but by local thermal breakdown (quench) [21]. The BCP treated $(80-100 \mu \mathrm{m})$ large grain $\mathrm{Nb}$ cavities reached up to

\footnotetext{
${ }^{1}$ The polycrystalline $\mathrm{Nb}$ sample, made up of cavity material, was EP'd up to $144.8 \mu \mathrm{m}$ in the first step using $\mathrm{H}_{2} \mathrm{SO}_{4}(95 \%)$ and $\mathrm{HF}(46 \%)$ in a volume ratio of 9:1, and was mounted inside a cavity during final $43 \mu \mathrm{m}$ EP and HPR. The sample surface showed the microroughness of $\sim 0.2 \mu \mathrm{m}$ and grain boundaries of $1-2 \mu \mathrm{m}$ step height. The cavity reached $26.5 \mathrm{MV} / \mathrm{m}$ without $\mathrm{x}$ rays being detected.
} 

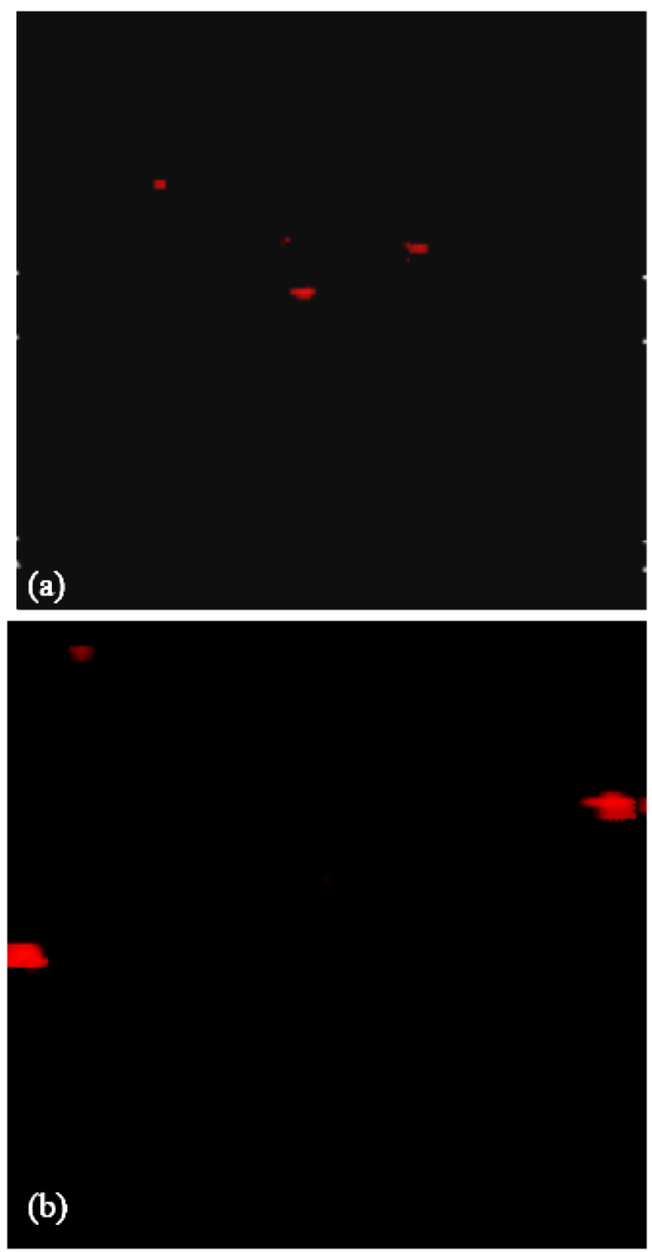

FIG. 2. (Color) $E$ maps for (a) SCNb1 and (b) SCNb5, over the area of $(5 \times 5) \mathrm{mm}^{2}$ using a $100 \mu \mathrm{m}$ conical anode at tip-tosample distance of $25 \mu \mathrm{m}$ in (a) and $20 \mu \mathrm{m}$ in (b). The red dots reveal five and three emitters at onset fields (for $2 \mathrm{nA}$ ) of about 200 and $250 \mathrm{MV} / \mathrm{m}$, respectively.

$\sim 30 \mathrm{MV} / \mathrm{m}$, while a single-cell cavity of single crystal $\mathrm{Nb}$ showed field up to $38 \mathrm{MV} / \mathrm{m}$ [22]. Though a systematic study is required for better understanding on the effect of surface preparation on cavity performance, for this purpose eight new large grain $\mathrm{Nb}$ nine-cell cavities have been fabricated and will be tested at DESY after BCP treatment only.

\section{B. Grain boundary effects and low temperature heat treatment}

Present high quality $\mathrm{Nb}$ samples should be informative to study any grain boundary effect on FE, due to the presence of either no grain boundary or very few but large grain boundaries easily visible on the sample surface. However, no FE was observed from grain boundaries up to the field of $250 \mathrm{MV} / \mathrm{m}$ from any of the as-prepared large grain $\mathrm{Nb}$ samples.

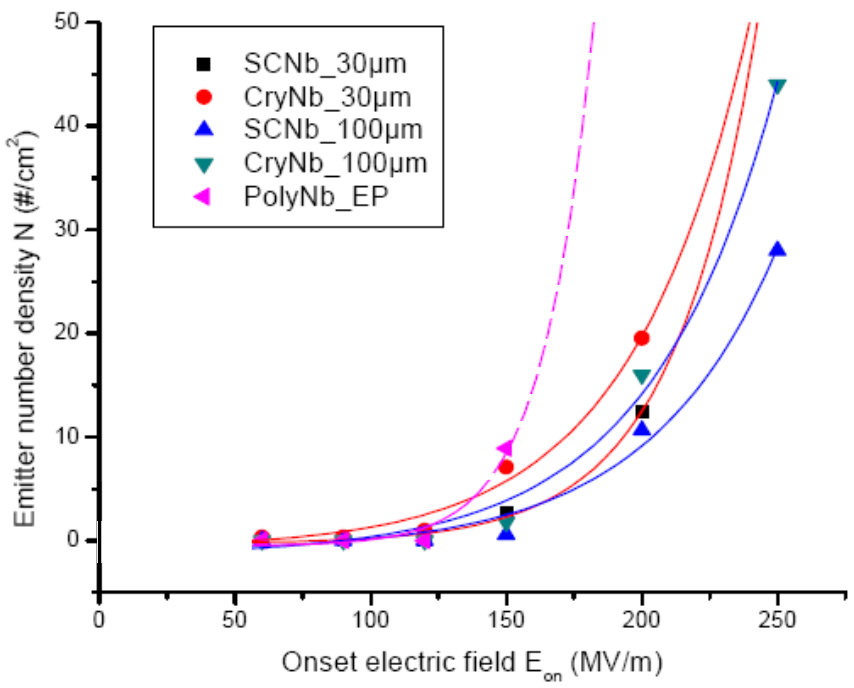

FIG. 3. (Color) Emitter number density vs applied electric field for different material removal. (Exponential fit lines: Red for $30 \mu \mathrm{m} \mathrm{BCP}$, blue for $100 \mu \mathrm{m} \mathrm{BCP}$, and magenta for EP polycrystalline $\mathrm{Nb}$ sample).

Heat treatment $(\mathrm{HT})$ of polycrystalline $\mathrm{Nb}$ cavities at low temperatures $\left(100-150^{\circ} \mathrm{C}\right)$ is used as a final preparation step, which improves the quality factor of cavities probably by the diffusion of oxygen from surface oxide into the bulk niobium [23,24]. Analogous to this cavity treatment, we have selected two samples LGNb3 and $\mathrm{SCNb} 4$ for low temperature heat treatments at $150^{\circ} \mathrm{C}$ for 14 and 8 hours, respectively. The corresponding FE maps made after HT are shown in Fig. 4. It is interesting to find that, on the LGNb sample, most of the emitting sites were activated near or on the grain boundaries, which are $89 \%$ at $250 \mathrm{MV} / \mathrm{m}$ and $63 \%$ at $300 \mathrm{MV} / \mathrm{m}$ of the total number of emitters. No features in SEM were observed corresponding to these emitters. Two grain boundaries possessing more emitters nearby have the step height of $\sim 12-15 \mu \mathrm{m}$, while the third one has the step height less than $0.5 \mu \mathrm{m}$, as measured by the profilometer [Fig. 4(a)]. Further it is notable that the strongest emission is observed at the intersection of three grain boundaries. On the other hand, the number of emitters for $\mathrm{SCNb}$ remained unchanged up to $200 \mathrm{MV} / \mathrm{m}$ as before $\mathrm{HT}$, while at $250 \mathrm{MV} / \mathrm{m}$, one new emitter appeared, and three old emitters disappeared [Fig. 4(b)]. Within statistical error, low temperature HT on SCNb did not show any change on its FE properties. Thus, the first evidence for grain boundary assisted FE is observed on LGNb, but only after HT. This is due to easier segregation of impurities along grain boundaries during HT. Our results also show the need for performing similar measurements at higher temperatures for comparison with $800^{\circ} \mathrm{C}$ annealing of cavities. More samples measurements are required for a better understanding of grain boundary effects on FE, and should be analyzed with SEM before and after HT. 


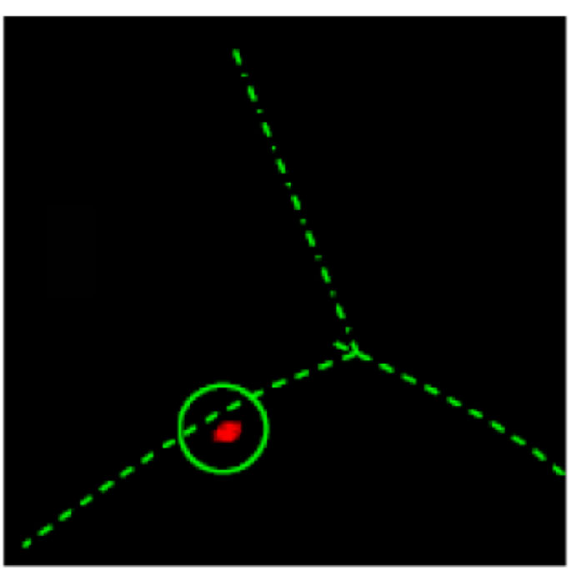

$250 \mathrm{MV} / \mathrm{m}$

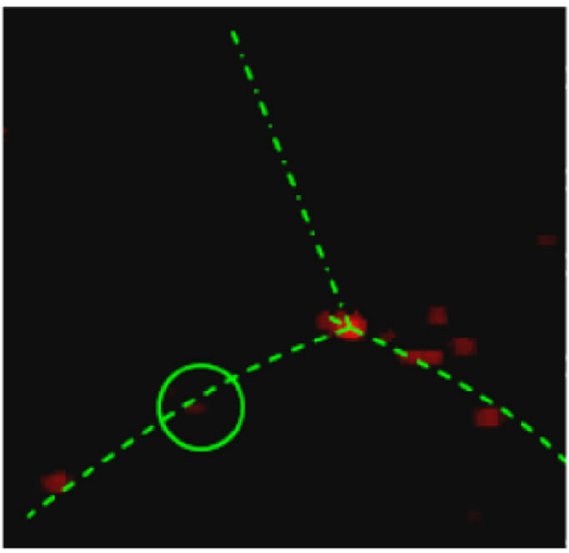

(a)
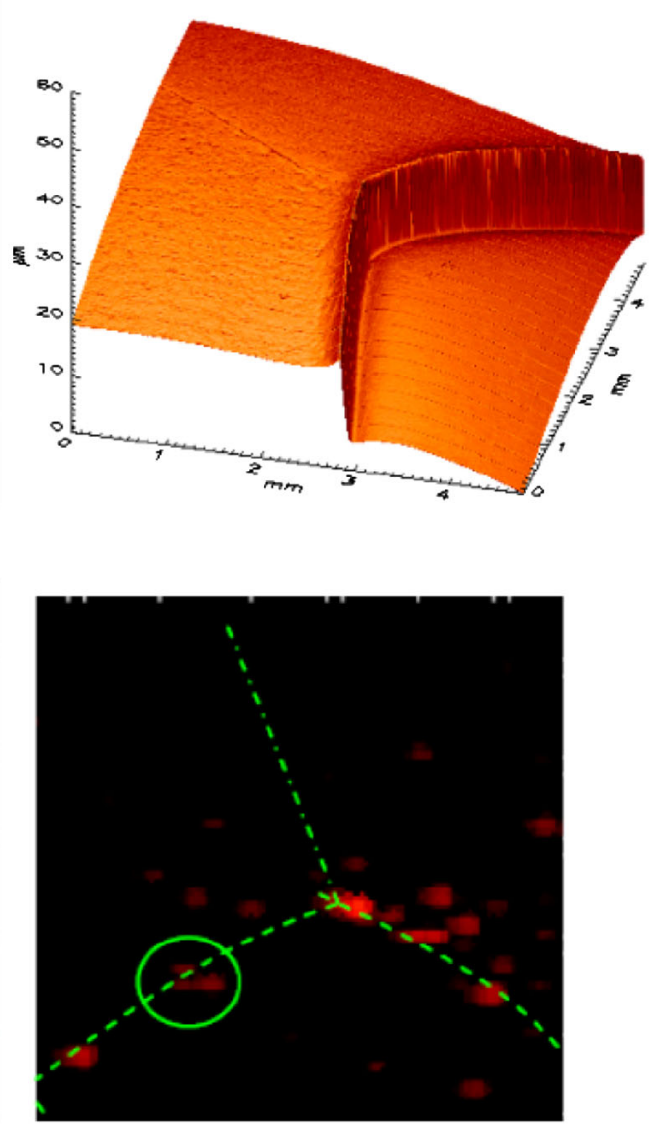

$300 \mathrm{MV} / \mathrm{m}$

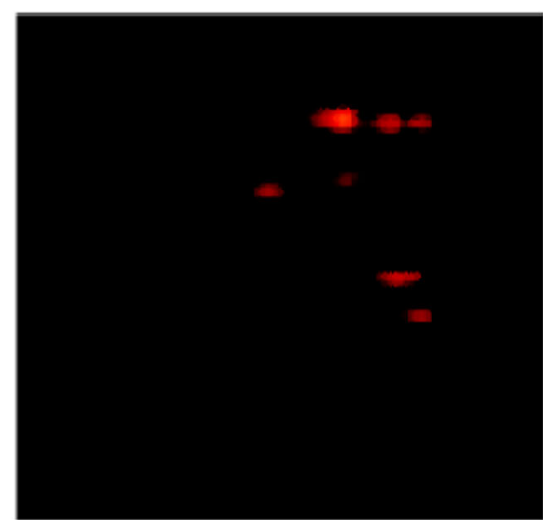

$250 \mathrm{MV} / \mathrm{m}$

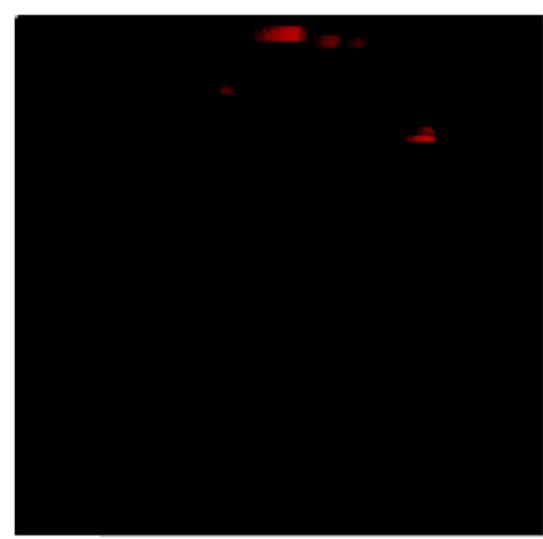

(b)
$250 \mathrm{MV} / \mathrm{m}$

FIG. 4. (Color) (a) $E$ maps of LGNb3, and surface profile showing grain boundaries. The encircled emitter is the one activated before HT, and dotted lines in the scan represent the grain boundaries. (b) $E$ maps for SCNb4: the vertical shift of scans before and after HT is an experimental artifact. All the scans were made over the same area of $(5 \times 5) \mathrm{mm}^{2}$, scanned before (upper) and after $150^{\circ} \mathrm{C}$ heat treatment (lower row) up to the given maximum fields. An anode of $100 \mu \mathrm{m}$ flat-apex diameter at the tip-to-sample distance of 20(16.5) $\mu \mathrm{m}$ for 250(300) $\mathrm{MV} / \mathrm{m}$ maximum field was used in these measurements.

\section{Single emitter investigations}

The strong emitters appearing in the FE maps of all scanned samples were localized in FESM as well as in SEM (later on) to study their individual FE characteristics with respect to their physical properties. In all cases, the observed emission confirmed Fowler-Nordheim (FN) theory [25] with local field enhancement [26-28]. Moreover, the phenomena of activation, deactivation, and stabilization of the emitters were generally observed in the continuous up and down cycles of applied electric fields during $\mathrm{I}-\mathrm{V}$ measurements. The typically observed values of field enhancement factor $\beta$ and emission area $S$ for different samples are given in Table II, where $\beta$ ranges from 24 to 56 and $S$ varies from $10^{-4}$ to $10^{-8} \mu \mathrm{m}^{2}$. Compared to this the $\beta$ typically observed in cavities are higher, lying in the range 60-120, which was observed for both the large grain as well as fine grain $\mathrm{Nb}$ cavities at surface fields of 40-80 MV/m.
The features observed for emitters in SEM investigations were generally surface irregularities (67\%) and particulates (33\%) with or without foreign elements present. On $100 \mu \mathrm{m}$ polished samples, the presence of a foreign element (aluminum) was detected only in one case [Fig. 5(a)], which might have come from the Al caps used in the transport system of the samples. The corresponding FN curves are changing in different increasing and decreasing modes of electric fields showing the emitters not being stable and might not be properly connected to the surface. The retrieved $\beta$ value of 26 and $S$ value of $6 \times 10^{-6} \mu \mathrm{m}^{2}$ seem reasonable for the $\mathrm{nm}$ size sharp features present on this flakelike object, which might dominate to the local field enhancement.

In the case of heat treated samples, it was interesting to find that the FN curves of all the emitters were rather straight, i.e., showing stable FN behavior probably due to good contact of emitters with the smooth surface. A typical 

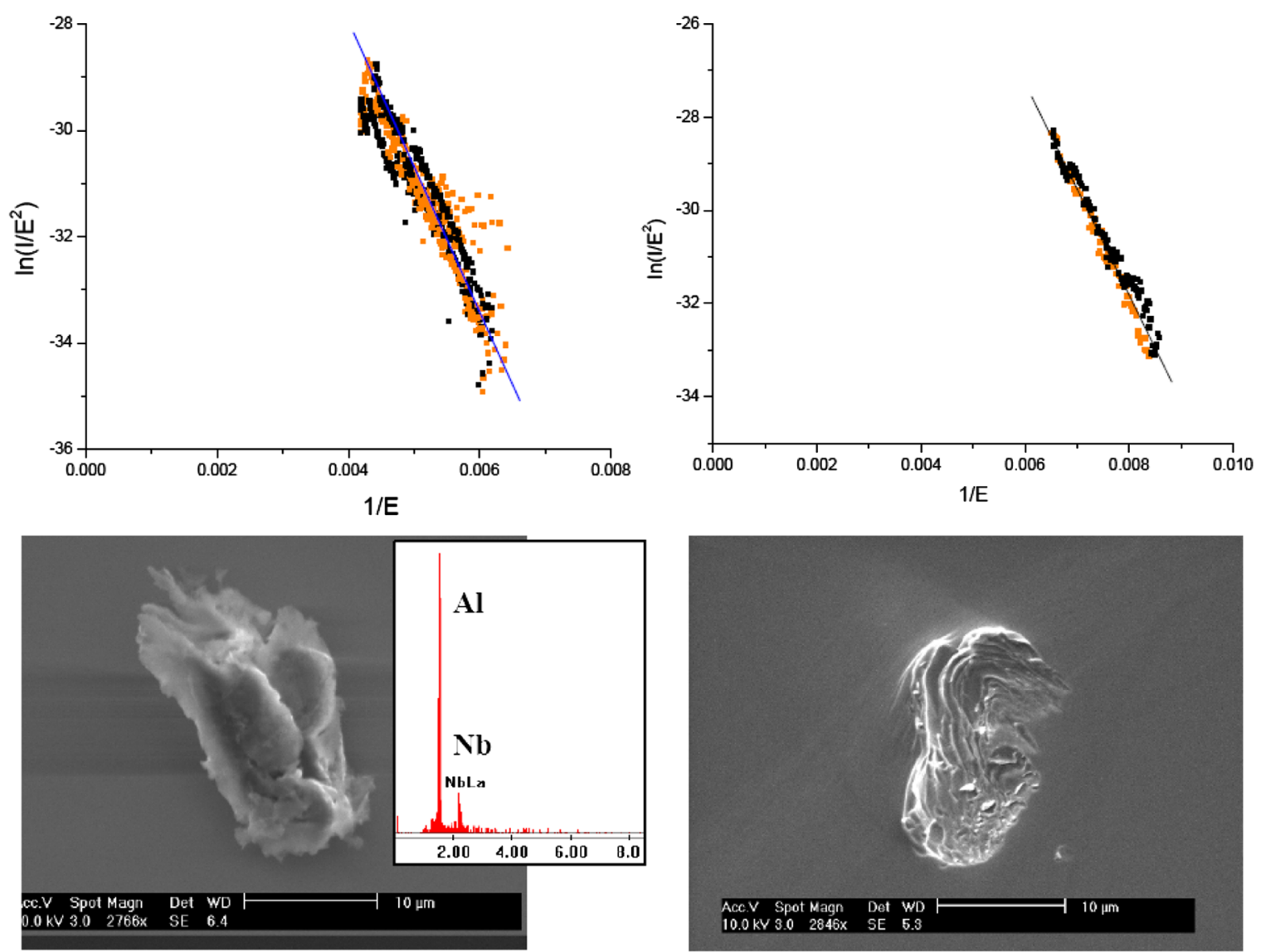

(a)

(b)

FIG. 5. (Color) I-V curves as FN plots of two emitters measured locally in FESM and corresponding SEM images (a) on SCNb7, showing an $\mathrm{Al}$ particulate, and (b) on $\mathrm{SCNb} 4$, a surface irregularity. In the plots, unit of I is $\mathrm{A}$ and of $\mathrm{E}$ is $\mathrm{MV} / \mathrm{m}$; measurement points (orange dots) are for increasing E, and (black dots) for decreasing E.

example is given in Fig. 5(b). The retrieved $\beta$ and $S$ values on HT samples were found in the range of (12-57) and $\left(10^{-3}-10^{-7}\right) \mu \mathrm{m}^{2}$, respectively, which are very reasonable for a nanometer to subnanometer size effective emission area.

\section{Intrinsic FE measurements}

The superior quality of presented single crystal $\mathrm{Nb}$ samples makes them suitable for intrinsic FE measurements. These measurements require absolutely clean cathode surface and anode tips, and a very small vacuum gap (down to $2 \mu \mathrm{m}$ ) for gaining high fields of $\sim 1 \mathrm{GV} / \mathrm{m}$ by means of the $5 \mathrm{kV}$ power supply. Samples SCNb4 of (111) and SCNb7 of (100) orientation were measured in defectfree areas with the freshly prepared $W$ anodes of 5-20 $\mu \mathrm{m}$ tip diameter. Since the measurements were very much sensitive to system vibrations, the anode tips as well as the sample surface were often damaged during measurements by microdischarges [inset of Fig. 6(a)]. The measured FN curves exhibit real FN-like behavior (Fig. 6), showing the onset of FE at fields higher than $1 \mathrm{GV} / \mathrm{m}$. Assuming $\beta$ equal to one for our smooth and single crystal samples, we retrieved the $\phi$ values of $\mathrm{Nb}$ with respect to different orientations from FN curves. The fitted mean $\phi$ values for $\mathrm{Nb}(111)$ and $\mathrm{Nb}(100)$ are 4.05 and 3.76 within the error of $17 \%$ and $27 \%$, respectively. It should be noted here that, despite the usual presence of surface oxides of about 30-60 A on niobium [29], the retrieved $\phi$ values are in accordance to literature data for the given orientations of $\mathrm{Nb}$ [30,31]. Earlier reported intrinsic measurements on chemically polished polycrystalline $\mathrm{Nb}$ have resulted in $\beta$ values of about 2 on considering a work function $\phi$ of $4 \mathrm{eV}$ for $\mathrm{Nb}$ [32]. On the basis of these results, we conclude that, according to the effective protrusion model [33], surface roughness surely enhances the $\beta$ of particulates and thus the field emission of polycrystalline $\mathrm{Nb}$ cavities.

\section{E. Emitter size vs onset electric field ( $\left.E_{\text {on }}\right)$}

In the past three years, we have measured many samples with different types of $\mathrm{Nb}$ surfaces (EP polycrystalline and $\mathrm{BCP}$ large grain or single crystal). The analysis of localized 

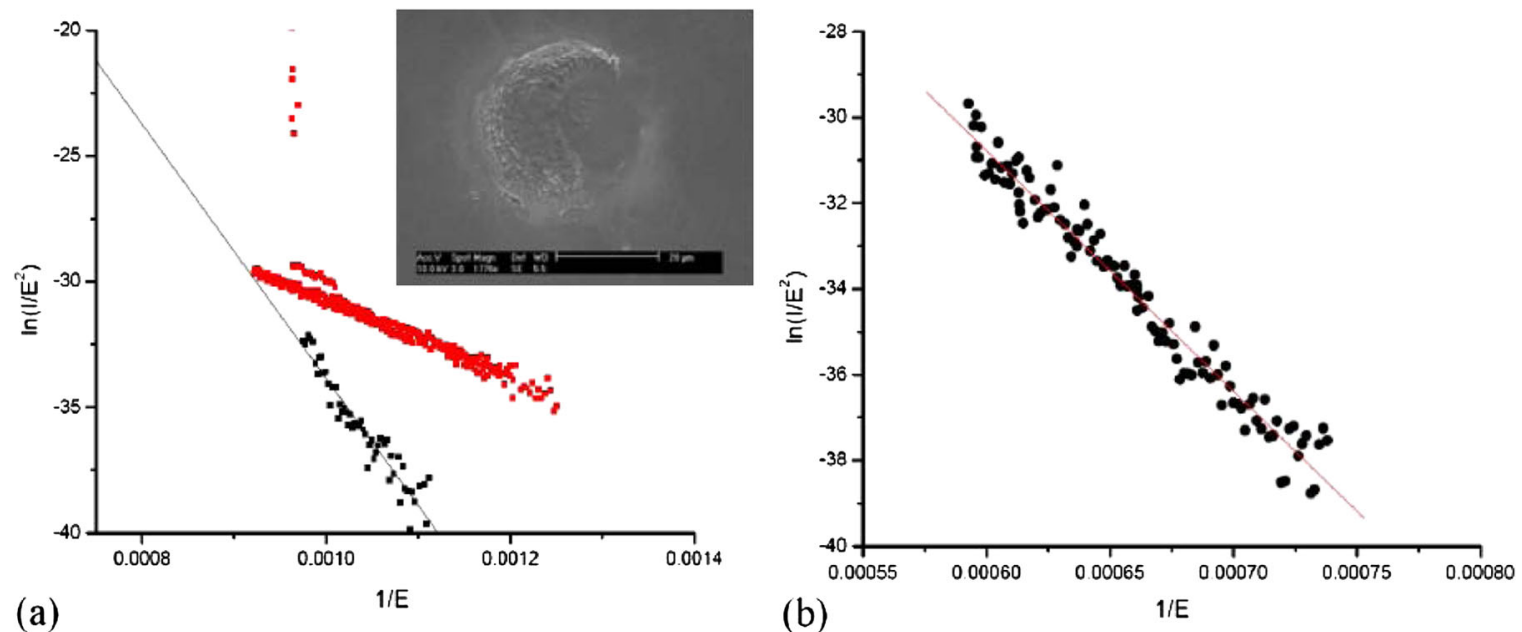

FIG. 6. (Color) I-V curves as FN plots locally measured on sample (a) SCNb4, showing the creation of an emitter by a microdischarge with resulting surface damage (inset SEM image) and (b) SCNb7, showing intrinsic field emission of $\mathrm{Nb}(\beta=1, \Phi=4 \mathrm{eV})$.

emitters in FESM and SEM has resulted in a suggestive plot (Fig. 7) of emitter size derived from SEM images vs corresponding onset electric fields. Particulate emitters are represented there with their average size and surface irregularities with their widths, because, e.g., for a scratch it is the parameter deciding over the height of the edges which causes enhanced FE. A huge spread in the emitter size is observed in the plot. The diagonal line, however, is referred as a threshold for the minimum emitter size and correspondingly achievable onset fields. Accordingly, to achieve an accelerating gradient of 30(40) $\mathrm{MV} / \mathrm{m}$ for XFEL [7]

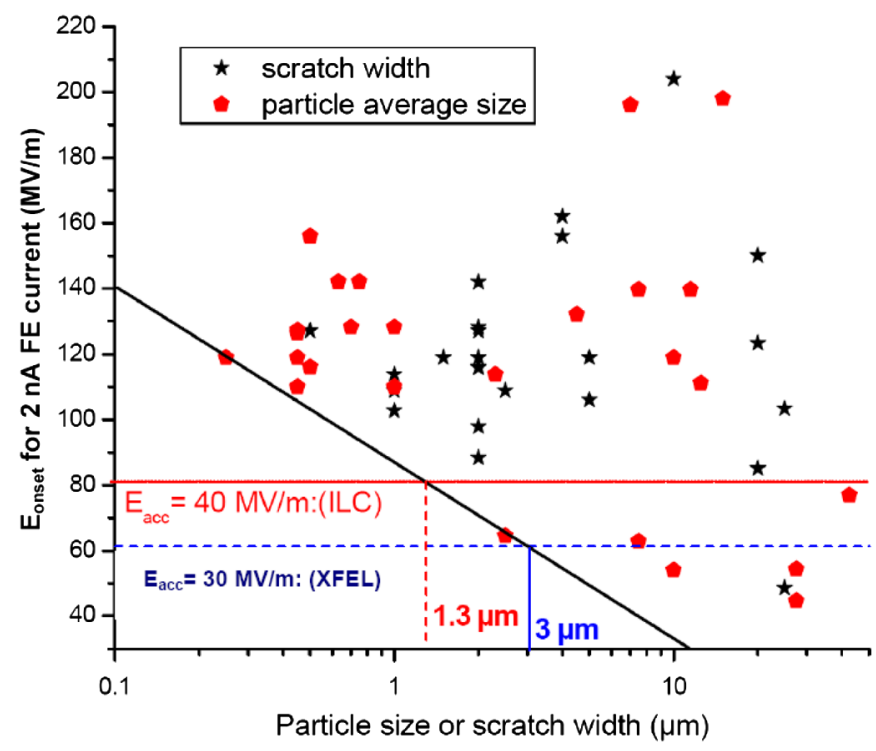

FIG. 7. (Color) Onset electric fields for $2 \mathrm{nA}$ FE currents vs geometrical size of all identified emitters found on different polycrystalline/single crystal/large grain niobium samples. The horizontal lines correspond to the proposed accelerating fields for future accelerators XFEL and ILC, and the diagonal line sets a corresponding threshold for tolerable defect sizes.
(ILC [8]), surface defects larger than 3(1.3) $\mu \mathrm{m}$ must be avoided. This result will surely be useful for the quality control of superconducting structures during the assembly of large accelerator projects.

\section{CONCLUSIONS}

Single crystal and large grain $\mathrm{Nb}$ samples treated with $\mathrm{BCP} / \mathrm{HPR}$ as a final surface preparation step have been found to show no FE up to surface electric fields of $150 \mathrm{MV} / \mathrm{m}$. The onset fields were slightly higher for the samples with a $100 \mu \mathrm{m}$ removed damage layer than those with $30 \mu \mathrm{m}$, and also for single crystals compared to large grain samples due to reduced surface roughness. Heat treatment of large grain $\mathrm{Nb}$ sample at $150^{\circ} \mathrm{C}$ for 14 hours has given first evidence for grain boundary assisted field emission. Intrinsic FE measurements revealed anisotropic $\phi$ values of 4.02 and 3.8 for (111) and (100) orientations of $\mathrm{Nb}$, respectively. From the past three years enhanced FE investigations on different $\mathrm{Nb}$ surfaces, a correlation between size of emitters and onset fields is obtained, which sets a threshold for the tolerable defect size to achieve the envisaged accelerating gradients in superconducting cavities reliably.

\section{ACKNOWLEDGMENTS}

We would like to acknowledge C. S. Pandey for support on the reinstallation of the oven in FESM, and A. Matheisen for electropolished niobium samples. We thank the Electrical Engineering Department at BUW for providing SEM and EDX facilities. Stimulating discussions with W. Singer and D. Proch from DESY are appreciated. The support of the European Community Research Infrastructure Activity under the FP6 "Structuring the European Research Area" program (CARE, Contract No. RII3-CT-2003-506395) is gratefully acknowledged. 
[1] http://flash.desy.de.

[2] https://neutrons.ornl.gov/.

[3] http://www.orau.org/ria/.

[4] G. Ciovati, in Proceedings of LINAC, Knoxville, Tennessee, 2006 (Report No. FR1004).

[5] P. Kneisel and B. Lewis, in Proceedings of the 7th Workshop on RF Superconductivity, Gif sur Yvette, France, 1995, edited by B. Bonin, p. 311.

[6] A. Dangwal, G. Müller, D. Reschke, K. Floettmann, and X. Singer, J. Appl. Phys. 102, 044903 (2007).

[7] TESLA/XFEL TDR supplement, DESY, Hamburg, Germany, 2002; http://xfel.desy.de.

[8] Proceedings of the first ILC workshop 2004, KEK, Tsukuba Ibaraki, Japan; http://www.interactions.org/ linearcollider.

[9] P. Kneisel, G. R. Myneni, G. Ciovati, J. Sekutowicz, and T. Carneiro, in Proceedings of the 21st Particle Accelerator Conference, Knoxville, 2005 (IEEE, Piscataway, NJ, 2005), p. 3991.

[10] G. Ciovati, P. Kneisel, and A. Gurevich, Phys. Rev. ST Accel. Beams 10, 062002 (2007).

[11] P. Niedermann, N. Sankarraman, R. J. Noer, and O. Fischer, J. Appl. Phys. 59, 892 (1986).

[12] E. Mahner, Part. Accel. 46, 67 (1994).

[13] R. J. Noer, Appl. Phys. A 28, 1 (1982).

[14] A. Dangwal, D. Reschke, and G. Müller, Physica C (Amsterdam) 441, 83 (2006).

[15] E. Mahner, N. Minatti, H. Piel, and N. Pupeter, Appl. Surf. Sci. 67, 23 (1993).

[16] D. Lysenkov and G. Müller, Int. J. Nanotechnology 2, 239 (2005).

[17] TESLA Technical Design Report, DESY, Hamburg, 2001.

[18] A. Matheisen, H. Morales Zimmermann, B. Petersen, M. Schmökel, and N. Steinhau-Kuehl, Proceedings of the 21st Particle Accelerator Conference, Knoxville, 2005 (Ref. [9]).
[19] E. Mahner, P. Kneisel, N. Pupeter, and G. Müller, in Proceedings of the 6th workshop on RF Superconductivity, Newport News, Virginia, 1993, p. 1085.

[20] P. Kneisel, in Proceedings of the 11th Workshop on RF Superconductivity, Travemuende, Germany, 2003 (Report No. TuO02).

[21] H. Padamsee, J. Knobloch, and T. Hays, RF Superconductivity for Accelerators (John Wiley \& Sons, New York, 1998).

[22] P. Kneisel, G. Ciovati, W. Singer, X. Singer, D. Reschke, and A. Brinkmann, in Proceedings of the 11th European Particle Accelerator Conference, Genoa, 2008 (EPS-AG, Genoa, Italy, 2008), MOPP136.

[23] B. Visentin, Y. Gasser, and J.P. Charrier, in 12th Workshop on RF Superconductivity, Ithaca, 2005 (Report No. TUP05).

[24] G. Ciovati and P. Kneisel, Phys. Rev. ST Accel. Beams 9, 042001 (2006).

[25] R. H. Fowler and L. Nordheim, Proc. R. Soc. A 119, 173 (1928).

[26] I. Brodie, J. Appl. Phys. 35, 2324 (1964).

[27] F. M. Charbonnier, C. J. Bennette, and L. W. Swanson, J. Appl. Phys. 38, 627 (1967).

[28] R. J. Noer, P. Niedermann, N. Sankarraman, and O. Fischer, J. Appl. Phys. 59, 3851 (1986).

[29] J. Halbritter, Appl. Phys. A 43, 1 (1987).

[30] R. Pantel, M. Bujor, and J. Bardolle, Surf. Sci. 62, 589 (1977).

[31] I. A. Podchernyaeva, G. V. Samsonov, and V. S. Fomenko, Izv. Vyssh. Uchebn. Zaved., Fiz. 12, 42 (1969).

[32] T. Habermann, Ph.D. thesis, University of Wuppertal, 1999.

[33] M. Jimenez, R. J. Noer, G. Jouve, J. Jodet, and B. Bonin, J. Phys. D 27, 1038 (1994). 